\title{
11. Systematic approaches to social protection
}

Chris de Neubourg, Victor Cebotari and Julia Karpati

\subsection{INTRODUCTION}

Studying a set of social protection instruments as belonging to a system clarifies the role of each of the relevant components and discloses how the defined collection of instruments answers underlying social problems. The analysis of a set of social protection instruments, through a systems lens, reveals the content and scope of the (implicit) social contract that a society is willing to accept, and/or indicates how the promises made in the social contract, which regulate societal solidarity, can be better served by improving the effectiveness and efficiency of the policy instruments. A systematic approach to social protection provides a technical analysis of how the components of a social protection policy fit together, revealing, on the one hand, how much the members of a society are willing to pool their risks and their resources, and on the other hand, how effectively and efficiently that is actually done. The social protection system analysis can, however, not formulate an answer to the ideological and political questions about how much and what type of social protection a society should offer to its members; it only facilitates the discussion about how to organise the political choices in an effective and efficient way.

A set of social protection instruments applicable to a country can be regarded as a system: a systematic approach to social protection describes and analyses the elements of the social protection 'system' in a comprehensive way. When comprehensively done, a systematic analysis reveals the underlying ideology of a set of social protection instruments (or how much and how solidarity in a society is organised) and at the same time also reveals how well the organisation functions in terms of effectiveness (reaching the objectives set) and efficiency (reaching the objectives at the lowest possible cost).

A social protection system description (or mapping) provides an overview of the components of the social protection system at a certain point in time for a particular country. Moreover, it provides details on each of the components in terms of eligibility, benefits, financing, organisation and administration.

A social protection system analysis studies whether and how these components fit together in a technocratically harmonious way: it draws attention to potential contradictions, inconsistencies, coverage gaps and coverage duplications and it compares target groups, risk coverage, administrative procedures, benefit levels, replacement rates and eligibility conditions across the components of the system. ${ }^{1}$

Besides these straightforward approaches to social protection systems, the scarce literature referring to systematic approaches to social protection often adopt a normative approach implying what a social protection system 'should' or 'needs to' be. For example, the definition

1 Or it pays attention to demand/needs, coverage, effectiveness, sustainability and coherence (OECD 2018). 
given by the German agency for international cooperation is interesting and illustrative in this context:

A systematic approach to social protection is intended to ensure that people are covered against risks throughout their entire lives. Individual social protection tools such as basic insurance and social insurance are efficiently interlinked. In the policy formulation process, social protection strategies are to be coordinated with those of other sectors, such as employment and food security, so as to increase effectiveness, sustainability and resilience of the population. (GIZ 2020,2)

The italicised parts of the definition contain normative elements, as follows:

- All-encompassing scope: a social protection system needs to cover all the risks throughout the lifecycle.

- Internal consistency in all aspects of design and implementation should be guaranteed and, where possible, the components should be integrated.

- External consistency in all aspects of design and implementation should be guaranteed.

Integrated social protection systems as described above are hardly observed in the real world although there are increasing efforts to move towards better integrated systems. The reality of most countries, however, suggests that social protection interventions are seldom designed as parts of a systematic response to the general need for risk pooling or as a section of a comprehensive social contract setting the framework for how a society organises the mechanisms for coping with problematic events or situations. Quite the contrary, the installation of new social protection instruments is often considered in isolation.

In almost all countries, single social protection interventions are introduced separately to address a particular concern, a looming crisis or to respond to social or political pressure, and little attention is given to make it fit well into the rest of the social protection system. ${ }^{2}$ Early industrialising countries like (parts of) the United Kingdom, France and Belgium, with a social protection tradition that dates back many decades, worked through a form of consolidation and rationalisation of their social protection (or welfare) system after the economic crises in the last decades. An increasing number of low- and middle-income countries make efforts to integrate new initiatives into the existing safety net, but for the overwhelming majority of countries, the architecture of the social protection system is extremely complex, often encompassing hundreds of pieces of legislation and regulations. ${ }^{3}$

This chapter adopts a pragmatic and technocratic view on systematic approaches to social protection, by regarding any collection of social protection tools installed in a particular country as a 'system'. Each of these systems can be mapped and analysed and conclusions can be made on their scope and internal and external consistency in all aspects of design and implementation. National systems may therefore be more or less 'systematic', more or less internally consistent, more or less effective (realising the objectives set) and more or less efficient (providing the services at the lowest cost). We accept that the scope of national systems may vary according to the underlying political preferences or ideology, but we will

2 For details on the historical developments in social protection and the welfare state see among others: Trattner (1999); Fraser (2017); Vis (2010); van Kersbergen and Vis (2014).

3 As an example: a recent mapping of the relatively new social protection system in an emerging economy, Morocco, revealed that the country had more than 150 laws, regulations and benefits in 2015; see Chef du Gouvernment du Maroc and UNICEF (2016). 
use universal coverage in all aspects as the technical benchmark ${ }^{4}$ without implying that it should also be the most desired situation (see below). While the authors of this chapter have their own views on the desired scope, we acknowledge that other analysts and policy makers may hold other points of view.

Making a thorough mapping and analysis of all social protection systems is important to study how well every element of the systems fits together, and to draw attention to contradictions, inconsistencies, overlaps in coverage, benefit levels and eligibility conditions and coverage gaps for the purpose of improving effectiveness and efficiency.

Section 11.2 discusses the theoretical basis on which social protection instruments can be seen as components of a single system; they all have a function as a tool for managing livelihood risks. That does not, however, imply that there is a single instrument available for every separate risk, nor that every risk can be covered by only one type of social protection instrument. In the portfolio of social protection system instruments, both substitutes and complements can exist. In the context of a systematic approach, these are very important features, and these features are elaborated in Section 11.4. Prior to that section, Section 11.3 discusses to whom social protection can be offered. Finally, Section 11.5 discusses four types of systems that, while differing in their political orientations and preferences, are all set up to be systematically integrated and systematic in a technocratic and normative way. A concluding section referring to toolboxes aimed at mapping and analysing social protection systems closes the chapter.

\subsection{SOCIAL PROTECTION AS LIVELIHOOD RISK MANAGEMENT}

Social protection interventions all belong to a family of policy measures, which makes it meaningful to map and analyse social protection instruments as a system with varying degrees of integration in scope, design, financing, implementation and administration across countries. The underlying idea is that social protection interventions all belong to a kind of family of policy measures. This section elaborates how social protection instruments of varying scope, nature and eligibility criteria have commonalities that justify being regarded as components of an overarching social protection system. For example, what do social assistance benefits for the poor, school meals subsidies for children or pension benefits for the elderly have in common with health insurance and parental leave options, to justify that these can all be regarded as components of an overarching social protection system? We answer this question through the conceptualisation of social protection as a framework for risk management and the consequent implications for the scope of a social protection system, and for defining which authorities should be responsible for assisting members of society with managing these risks.

\footnotetext{
4 'Universalism' in this context is used to describe a situation under which all residents/citizens are covered under a rights-based social protection system for all major livelihood risks that they may encounter. It is every country's political choice whether universalism is a desirable situation or whether gaps between the actual coverage and a universal coverage are accepted. Obviously, it is possible to regard universalism as the best possible standard for a social protection system, but that is a political opinion that is not necessarily shared by everyone.
} 
The purpose of social protection is to provide people (citizens, residents, contributors or clients) with protection against specific risks which may occur throughout their life cycle. Some of these livelihood risks are not age specific and others are necessarily tied to a certain period in the life cycle. Perhaps the most fundamental risk of all is the risk that one does not have the (financial) resources to survive in the society wherein one is living. That risk is called poverty, ${ }^{5}$ and theoretically, all members of a society are vulnerable to that risk. The risk of becoming ill and not being able to afford the healthcare services that are needed to be cured is also a risk to which potentially all members of a society, no matter their age, are vulnerable to. Most co-variant risks related to (man- or nature-made) disasters such as financial crises, flooding, earthquakes, droughts and pandemics affect all members of a society, and often at the same time. ${ }^{6}$

The main livelihood risks related to a certain period in the life cycle are:

- Childhood-related risks: starting with pregnancy-related risks, childhood diseases and immunisation, access to all services that children need in order to be able to develop to their full potential including all forms of education, healthcare and protection.

- Longevity risks: the risk of not having enough resources towards the end of one's life at the moment that earning capacities have dwindled.

- Income loss risks: risks related to all kinds of loss of income-generating opportunities during active periods in one's life, including short-term illnesses, unemployment, disability and accidents (work-related and others).

Social protection interventions aim to cover one or more of these categories of risk, usually by guaranteeing financial or in-kind resources to cope with the materialisation of the risk. The interpretation of social policy or social protection policy as social risk management dates back two decades and provides a comprehensive framework to analyse social protection instruments as part of a social protection 'system' (Holzmann and Jorgensen 1999; de Neubourg and Weigand 2000).

The risk management framework also allows us to conceptualise important discussions on the scope of social protection systems. The two main questions that need to be addressed to decide on the scope of social protection systems are:

1. To what extent does the management of the livelihood risks need to be 'social'?

2. Who needs to be covered by the 'social' protection system?

In answering the first question, it is clear that in the absence of social protection instruments, risks and negative states in the event of risk are managed by other channels - after all, "public

\footnotetext{
5 While a solely financial conception of poverty does not encompass all the ways in which poverty can be experienced, we refer to it here expressing the quintessential characteristic of the concept; it is clear that societies differ in the way they define the "necessary minimum to survive in the society wherein one lives' and the way and methods to measure that minimum as a benchmark (see for example Notten and de Neubourg 2011 for a comparison between the United States and Europe in that respect).

6 Stating that all members of a society (or all members of a particular age cohort) are vulnerable to a risk does not imply that all members of a society have equal probabilities to being confronted with that risk; some groups in a society are more vulnerable than others.
} 
authorities' are only one of the corners of the 'Welfare Pentagon'7 (de Neubourg 2002). When confronted with (the costs of) a livelihood risk, people will seek assistance through the other corners of the welfare pentagon when forms of social protection implanted by public authorities are lacking. Assistance by families, social networks and membership organisations (such as unions, churches, charities) are social and informal forms of risk management which can provide effective protection against the costs linked to livelihood risks. Apart from informal social channels, economic agents can use markets to seek individual forms of protection against livelihood risks, such as private insurance, savings and credit accounts. Retrenchment and shrinkage of public social protection interventions (i.e. of the social protection system) either in terms of coverage or benefit adequacy, such as due to austerity measures or changes in voter preferences, will necessarily enhance the importance of the informal and market channels of the welfare pentagon; the public social protection system and the informal and market forms of social protection are necessarily partial substitutes and communicating vessels. Protection provided by markets and informal channels aiming at safeguarding livelihoods is 'social' as these channels all require the intervention of social groups and other people; however, we do not regard them as parts of a social protection system.

The essential characteristic of 'social protection' is its direct link to the social contract and the rights of citizens or residents to be protected from livelihood risks. Only public authorities can guarantee that right, while individuals, groups, markets and charities cannot. Health insurance, as an example, is only a part of social protection if the right to access to (defined) health services is guaranteed by law or regulation, and this access can be enforced by legal action if necessary. This also applies to other parts of social protection systems. If this part of the definition were to be relaxed, there are no reasons why risk protection instruments such as car insurance and private assistance of parents to children would not be considered part of a social protection system. In that sense the old-fashioned and seldom-used term 'social security' would still be a more convenient concept.

The definition of social protection as a publicly guaranteed form of social protection does not, however, imply that non-for-profit organisations, for-profit firms, charities, parastatal institutions and non-governmental organisations could not deliver parts of social protection interventions. Defining social protection as rights-based arrangements leaves the financing, implementation and administration of the arrangements to be elaborated and the choices are manifold in this respect. Neither does the definition of social protection as publicly guaranteed forms of social protection imply that the rights on access to the benefits of the social protection interventions should be universal; it is perfectly possible that only parts of the population are covered or that the right is reserved for persons fulfilling certain criteria such as being employed in a particular sector, being a civil servant or having contributed into the system for a defined minimum period of time.

We talk in the context of this contribution about 'social', or public forms of protection, when:

- public authorities at some level have taken responsibility for at least the regulation and possibly the administration, organisation and production of transfer mechanisms and insurances;

\footnotetext{
7 The 'welfare pentagon' conceptualises the idea that in principle every person can use five channels to deal with livelihood issues and risks: families, social networks, markets, membership organisations and public authorities.
} 
- some form of formal risk pooling or solidarity underlies the financing of the protective interventions; and

- the rights of participants and beneficiaries are guaranteed by law and regulations.

It should be noted that the emphasis on the public character of provisions in the definition above narrows social protection down by excluding private or semi-private provisions that can equally protect participants or beneficiaries. Undeniably, purely private (health) insurances, private mutual (micro-)insurance schemes, transfers between family members and transfers between households and straightforward, more anonymous, charity all protect the participants and the beneficiaries; in our view, however, they are not part of public social protection unless access to their 'benefits' is guaranteed by laws and regulations. The definition adopted in this contribution is not necessarily shared by all scholars nor by all contributors to this handbook.

\subsection{SOCIAL PROTECTION FOR WHOM?}

Section 11.2 attempted to unpack the parameters that define the scope of social protection systems, thereby demarcating what social protection entails in terms of content. Equally important for defining the scope of social protection systems is determining to whom social protection is offered.

Social protection systems differ in their principal answer to the question: who in a society should be covered by the social protection instruments? The choice between the following three extreme positions, as the baseline for building a system, is influenced as much by political preferences and ideology as by effectiveness and efficiency considerations. The three baseline positions can be described as follows:

1. Universal coverage: the entire population should be covered since livelihood risks are assumed to be the same for every person (allowing for varying probabilities) and thus everybody needs protection against these risks. This does not necessarily imply that everybody should be covered for the same risks, by the same eligibility criteria, benefit amounts or organising institutions. Universal coverage of the population under the protection system implies that the population is entitled to receive a benefit in the event a particular livelihood risk materialises, assuming that the eligibility criteria for a set of social protection interventions is met. Universal coverage does not imply that the entire population is guaranteed to receive a benefit at some point. For example, the entire population can be covered by unemployment insurance. That, however, does not mean that all members of the population are guaranteed to become unemployed and consequently receive a benefit at some point in time. The same holds for means-tested social assistance: the entire population can be covered by social assistance, but only a small fraction of the population will ever receive a social assistance benefit.

2. Residual coverage: only people who are not able to afford private market solutions to the livelihood risks or who are otherwise not able to organise informal social protection should be covered by the social protection system. The degree of selectiveness and thus the size of the residue may differ across countries and systems. The position that the social protection system should primarily cover only the defined poor in a society is a special case of the residual position. This position often states that covering the entire population is not politically or morally desirable or not possible (i.e. not affordable), and therefore only 
the poorest segments of the population should be covered by the social protection system or parts thereof. The poor are implicitly regarded as people who are not able to afford the market solutions to dealing with livelihood risks or are not able to mobilise informal social protection. More precise definitions of the poor as a group as well as the conditions under which financial or other constraints define eligibility for social protection are described in detail in other chapters of this handbook.

3. Coverage as privilege: only people belonging to specific groups in society are entitled to social protection. These groups may be professional groups, groups of people deemed deserving special attention or other groups. In many countries, public servants and the members of the military belong to groups subject to social protection interventions from which the rest of the population is excluded. The same applied and still applies to members of society that are especially protected due to their social status (sometimes defined as war veterans, freedom fighters or heroes).

In practice, combinations of elements driven by the second and third positions as described above are easy to imagine and to observe. It is much harder to think about combinations of the first position, on the one hand and the second and the third positions on the other hand. Strictly spoken, these combinations are only possible when groups are singled out to receive universal coverage while others are subject to residual coverage or coverage based on privileges. That would, for example, be the case if children and/or the elderly are universally covered, while the working-age population is residually covered or covered by privilege.

Debates between the proponents of these extreme positions are often complicated by the use of moral arguments which introduce elements of merit. From this perspective, only persons judged by society as 'deserving' assistance from social protection interventions in a certain form should be covered by a social protection system. This position sometimes leads to excluding critically vulnerable and socially excluded groups, such as people who have had a limited residence period in the country in question, and have thus not contributed into the social system for the required period of time for eligibility (resident non-citizens, refugees, migrants), people who have a criminal record, people who do not pay (enough) taxes or other groups who are regarded as 'marginal' to the mainstream in society, such as ethnic minority and Indigenous groups, or other minority groups.

In the remainder of this chapter, we take the position that universally covering the entire population is the benchmark for a social protection system - not as a moral standard, but as a standard that allows for analysing gaps between the actual situation and the theoretically universal coverage of the population. Once these gaps are mapped and analysed it would be logical to study the reasons for the gaps in the coverage and assess their legitimacy, against the prevailing moral, social and political standards and norms in the relevant society.

\subsection{A PORTFOLIO OF SOCIAL PROTECTION INSTRUMENTS: EFFICIENCY AND EFFECTIVENESS}

Section 11.2 argued that social protection instruments have a common ground as livelihood risk management tools. It would be tempting to think that there is a social protection instrument for every risk and that every risk can be covered by a single social protection instrument: that would make mapping and analysing systems relatively easy. 
The reality is, however, more complicated. This section argues that social protection instruments can be both substitutes and complements and that, therefore, making an analysis of a system in terms of effectiveness and efficiency is a complicated task.

\subsubsection{Social Protection Instruments Are Substitutes}

In a system of social protection, livelihood risks can be addressed using various instruments, whose functions substitute for each other. In other words, there is not necessarily a one-to-one relationship between any particular livelihood risk and a particular social protection instrument: many different risks can be covered by several different social protection instruments or by combinations thereof. This can be illustrated by four examples: income loss in the event of illness or unemployment by wageworkers, education for children, healthcare and management of longevity risks.

A social insurance benefit can cover the risk of income loss for wage earners during periods of short-term illness by guaranteeing a certain percentage of their regularly earned wage. The same risk of contingency-based income loss could also be covered by a simple social cash transfer out of a public fund in the event of illness, or by a labour market legislation compelling employers to continue paying the salary of an ill employee for the duration of their illness (in part or in full). These three channels - the cash transfer, the insurance pay-out or the continued wage - all are substitute instruments which address the same contingency. Except for in the case of employers being legally compelled to continue paying salaries of incapacitated employees, additional labour market legislation is necessary in order to guarantee that the ill employee does not face further risks of job loss due to absence caused by illness. Covering income losses due to job losses can be addressed by a specific voluntary or compulsory unemployment insurance, by public works, by tax-based single payments or by a universal basic income (UBI).

Ensuring that all households in an economy are able to send their children to school can be supported by many social protection instruments. Free or widely affordable education at all levels, school waivers, schooling vouchers, universal child benefits, conditional child benefits, universal educational grants for school equipment and books are all substitute instruments which serve the same purpose of enabling all children to have access to education and incentivise them to attend school regardless of household means. Many countries use several of these instruments at the same time.

Ensuring that all individuals have access to basic or even advanced healthcare services when needed can be realised using very different instruments, ranging from private insurance to social insurance, mutual insurance companies, payment waivers, vouchers and fiscal deductions, to completely free access to public healthcare services.

Longevity risks may be covered by a universal basic pension scheme, by compulsory social pensions through funded, unfunded or notional financing mechanisms, by regulated private pensions with or without tax relief or by a combination of all these instruments (as it is in many countries with developed social protection systems).

While one risk may be covered by different social protection instruments, one single social protection instrument can also be used to cover several risks at the same time. That holds especially true for (quasi-)universal cash transfers. A universal child benefit can make sure that parents are able to cover the diverse costs for their children, including paying for care, food, healthcare and education. In the same way, an educational grant may help to pay for all 
types of costs of the students and a social (universal or targeted) pension may cover several risks related to old age.

\subsubsection{Social Protection Instruments Are Complements}

While social protection instruments often stand alone, many of them are linked and intertwined. Survival and healthy development of children and the elderly often depend on the interplay of many social protection instruments at the same time. Children and the elderly can be subject to many risks simultaneously. Risk mitigation and coping strategies often require the presence of several complementary social protection instruments. For persons in the working-age population, several social protection instruments need to be in place to simultaneously cover a variety of risks that seldom occur at the same time, but easily could materialise over time. This set of instruments includes provisions against illness, disability (job- and non-job-related) and unemployment. A special complementary relationship exists between a broad range of social services and social protection instruments. For example, it is not very effective to have a well-organised health insurance system if the health services are not available: the insured would be insured against health risks, but the insurance would not be effectively giving access to health services. The same applies to educational grants that are only effective if there are decent quality schools, or food subsidies for young children to fight stunting and malnutrition if, at the same time, safe water and adequate sanitation are guaranteed to prevent development-inhibiting communicable diseases.

\subsubsection{Social Protection Instruments as Part of an Effective and Efficient System}

Pointing out that social protection instruments can be substitutes and complements is but a conceptual step in assessing whether the portfolio of instruments or the social protection system is effective and efficient. Assessing how well a collection of social protection instruments (including the legal frameworks, their design, their implementation and administration) fit together requires, as stated at the start of this chapter, a thorough analysis.

The Organisation for Economic Co-operation and Development (OECD) has established a toolkit for a social protection system review for analysing the effectiveness of countries in establishing a social protection system that responds to the needs of the people (OECD 2018). The OECD's toolkit distinguishes four stages for the assessment of a social protection system: needs, coverage, effectiveness and sustainability (OECD 2018), with efficiency assessment being part of the latter in the OECD terminology.

While a thorough discussion of all the parameters and indicators that are important when assessing the effectiveness and efficiency of social protection systems is outside of the scope of this chapter, it is important to stress several important questions that should be addressed:

1. Coverage of the risks/needs:

a. What is the legal coverage and effective coverage of each of the instruments and of the combination of instruments?

b. Are there parts of the risks or the needs of parts of the population that are left uncovered (coverage gaps)?

c. Are there parts of the risks combined with the population that are covered by several instruments (duplications)? 
2. Internal consistency: are the different instruments consistent with each other in terms of

d. definition of the beneficiaries?

e. eligibility criteria?

f. benefit levels and benefit durations?

g. financing (contributions and taxes)?

3. External consistency:

h. with related legislation?

i. with related tax and contribution regulations and rules?

j. with the reality on the ground?

4. Sustainability:

$\mathrm{k}$. Is the collection of instruments providing the best outcomes against the lowest costs?

1. Is the projection of expenditures for the instruments consistent with the fiscal, economic and legal reality?

m. Could the realisation of economies of scale in administration or the implementation of simplifications in the design lead to less expenditures?

The following examples illustrate the relevance of groups of these questions. ${ }^{8}$

The analysis of the coverage could, for example, reveal that in some regions, specific groups of elderly people are both covered by free health insurance and at the same time receive a subsidy to buy private health insurance, while similar groups in other parts of the country are receiving no protection guaranteeing access to basic health services at all.

The internal consistency analysis may reveal that people regarded or defined as having disabilities are receiving a disability benefit with a replacement ratio that is 10 per cent higher than the replacement ratio for those who have lost their job and are unemployed. Moreover, if the benefit duration of the disability benefit is longer than that of the unemployment benefit and the employer has to pay a higher premium for laid-off workers than for workers becoming disabled, both the employers and workers have strong incentives to use the disability social protection instrument rather than the unemployment insurance in the event that workers become redundant.

Checking external consistency is important in order to avoid situations wherein, for example, a parental leave benefit would be available for a number of days per year for fathers and mothers, while labour market laws would not force employers to provide job security for parents using the parental leave benefit.

The sustainability of a social protection system could be improved in situations wherein cost-benefit analyses would reveal that alternative administrative implementations of a social protection instrument would generate higher benefits at constant costs.

A note should be added on the dynamic efficiency and effectiveness over time (or the sustainability of the system). The social protection system analysis could reveal that the financial sustainability of a system is challenged because of demographic changes (e.g. ageing population) or otherwise shrinking resources for financing the expenditures. Policy revision could then seek to expand the sources of social contributions beyond labour as well as making labour market investments in long-term diversified sources of funding.

Finally, it should be noted that the ultimate analysis of whether a collection of social protection instruments is an effective and efficient system with harmonised administrations and 
rules and integrated services where possible cannot be answered on purely technical grounds. The technical information is important as the basis for the assessment, but the full assessment can only be done if the intentions and the underlying objectives are taken into consideration. In the end, one needs a judgement on the importance of the degree of moral hazard, on the occurrence of adverse selection and on the potential invasion of the fiscal space both in/by the separate instruments and in/by the system. That means seeking answers to questions such as: how important are disincentives to work or to be self-reliant? How important are exclusion and inclusion errors in targeted benefits? How important are disturbances in the fiscal incidence and how acceptable are the distributions of costs and benefits of the social protection system?

Attempting to answer these questions requires the technical analyses as indicated above, but the ultimate assessment is only possible within a normative framework. The assessment is only possible if the answers to these questions are linked to the political and ideological preferences. What looks like a balanced system, providing acceptable solutions to the trade-offs that are always present to some, will be judged as an unsustainable and dangerous collection of instruments by others.

The fact that the ultimate assessment of systems may be ideologically driven is, however, no excuse not to make a valid and robust technical analysis.

\subsection{TYPES OF PORTFOLIOS: TYPES OF SOCIAL PROTECTION SYSTEMS}

This section explores whether prototypes of systems can be distinguished by taking a closer look at four attempts to formulate coherent frameworks as the basis of a social protection system. Each of the frameworks represents a particular view on how social protection systems could be organised and could serve as the blueprint for action in countries if policy makers chose the underlying presumptions of the respective framework. Each of these particular views is linked to ideas about coverage as explained in Section 2. The four frameworks are also chosen to reflect on social protection initiatives that have been widely implemented in a variety of countries across the globe and reflect differing approaches to designing social protection systems. They are described in brief below and are expanded upon in the following section.

1. The system in 11 European countries has been structured to provide 100 per cent social protection coverage for a wide range of risks for the entire population. The main features distinguishing this system from others are (a) the wide range of risks covered, and (b) the focus on the country's entire population. The 100 per cent coverage system has grown over a long period of time and is still evolving.

2. The social protection floor (SPF) initiative is a comprehensive minimum system of basic nationally defined guarantees endorsed by the United Nations under the initiative of the International Labour Organization. The initiative aims to provide inclusive coverage for children, the elderly, individuals who are unemployed and individuals with disabilities, in combination with a basic health insurance coverage. It is universalist in its approach but focuses on some of the basic life-cycle risks to be covered.

3. The idea to provide a $U B I$ is another variant of a universalist approach: it covers everyone in a society, but without paying attention to covering specific risks, and enabling recipients 
an element of choice and flexibility in how they choose to cover the event of risk. The element of choice and the flexibility of risk coverage are distinguishing elements of the UBI approach, in that it gives responsibilities to individuals as decision makers for tackling their vulnerabilities.

4. The Social Safety Nets (SSN) approach as propagated by the World Bank takes a very different approach; it is probably the best elaborated example of a system that is built around the idea that the purpose of social protection is to alleviate poverty for those at the bottom of the income distribution, sometimes nationally defined as the 'extreme poor'. Similar to the UBI framework, this approach focuses mainly on cash and in-kind transfers, along with a subset of other public social interventions, but provides them to only a selected fraction of the population.

There have been attempts to classify existing social protection systems as reflecting social, political and economic choices that countries have made concerning the parts of the population that needs/deserves to be covered, types of risks that need to be covered, the types of instruments that are going to be deployed and the level of protection that these instruments will provide. While no two national portfolios of instruments are identical, it may be appealing to categorise national social protection systems into a typology based on the similarities and dissimilarities between national portfolios. The best-known example of such a categorisation was made 30 years ago by Gøsta Esping-Andersen (1990) for the OECD countries. The slightly aged typology distinguishes liberal regimes, conservative regimes and social democrat regimes. Reforms and retrenchment of welfare states and periods of prolonged austerity have changed elements of each of the systems, up to the point where it is difficult to maintain Esping-Andersen's typology, although a meaningful categorisation can still be described (see Arts and Gelissen 2010; Vis 2010).

\subsection{PER CENT COVERAGE SYSTEMS IN EUROPE}

A blanket European social protection system does not exist, and the diversity of national social protection portfolios within the European Union is significant as social protection is mainly a national responsibility. The long history of state-organised social protection initiatives in many European countries has turned the European social protection systems into elaborate and developed 'welfare states'. In the latest World Social Protection Report (ILO 2020), we find 11 countries that provide a legal coverage ${ }^{9}$ to (nearly) 100 per cent of its population distinguished as children, mothers of newborns, persons with disabilities, unemployed older persons

\footnotetext{
9 Effective coverage is usually smaller than legal coverage; some groups in a society may be legally covered but may lack actual coverage due to lack of information, discrimination or other factors. Effective coverage should not be confused with the actual coverage being defined as the percentage of the population actually receiving a benefit at a point in time. That percentage is usually much smaller than 100 per cent by design. Means-targeted social assistance in the case of the 11 countries is provided to a tiny fraction of the population while still the entire population is covered (see de Neubourg et al. 2007). Likewise, unemployment benefits are only provided to the unemployed and maternity allowances only to mothers, while in both cases 100 per cent of the relevant populations are legally covered.
} 
and vulnerable groups (ILO 2020, table B.3).$^{10}$ In Austria, Belgium, France, Germany, Ireland, the Netherlands, the United Kingdom and the Scandinavian countries Finland, Denmark, Norway and Sweden, ${ }^{11}$ all these groups are fully covered by legally anchored social protection instruments. Moreover, in all these European countries at least 99 per cent of the population is covered by health insurance (ILO 2020, table B.13) and high-quality primary and secondary education is free, while high-quality tertiary education is accessible at low or zero cost in nine of the 11 countries. ${ }^{12}$

In all of these countries, social protection provisions are available to cover short-term illnesses and all forms of temporary and occupational-related disabilities. Caring for the most vulnerable in these countries is covered by a comprehensive targeted social assistance system in many cases supplemented with subsidies for housing and basic utilities.

The coverage of the entire population in all its subgroups reflects the basis of the social protection system in these European countries which is that citizens (and in many cases residents) who need assistance to face or mitigate the consequences of livelihood risks have a legal right to rely on the relevant state-initiated social protection intervention(s).

It should be noted that considerable differences exist between the 11 countries in the types of instruments that are used to guarantee the coverage, illustrating that social protection instruments are often substitutes as argued above. It is equally clear that guaranteeing that the entirety of the population is covered does not necessarily imply that poverty is inexistent or even close to zero. Poverty rates and remaining inequalities are determined by the adequacy, the replacement ratio of benefits and tax rules in addition to effective coverage. Even in a situation where the entire population is entitled to assistance when needed, it does not automatically imply that the assistance is adequate, and that the replacement ratios are high enough to avoid outspoken declines in financial resources or even overt poverty (for details on instruments, eligibility criteria, adequacy and replacement ratios in European Union countries see MISSOC 2020).

A final remark should be made regarding the influence of social protection on inequality. Despite the facts that (a) without the social protection system, the pre-tax/pre-benefit income inequality in the 11 European countries would be substantially higher and (b) that 10 of the 11 European countries rank amongst the most unequal countries in the OECD (the exception is the United Kingdom), it is also clear that the social protection system is not the only factor that leads to less or more inequality. These factors also include the economic prosperity of the country and the inequality in the pre-tax/pre-benefit income distribution (Mercader-Prats and Levy 2004; OECD 2020).

\subsection{SOCIAL PROTECTION FLOOR}

Contrary to the 100 per cent coverage systems, which provide a widespread legal coverage to social welfare through social protection instruments to (nearly) all residents in a country,

10 In Denmark, Sweden and the Netherlands the coverage of persons in unemployment is less than 100 per cent due to smaller legislative differences.

11 No countries outside Europe have a 100 per cent coverage as defined above (ILO 2020, table B.3).

12 Tertiary education is free for European Union students in Austria, Denmark, Finland, France, Germany, Norway and Sweden and there are very low tuition costs in Belgium and the Netherlands. 
the SPF initiative is conceived as a basic social security guarantee aiming at providing a basic income security and preventing the social exclusion of vulnerable groups in the country. ${ }^{13}$ The SPF provides a societal insurance against perpetuating deprivations in order to preserve dignity and empower people across the life cycle. The SPF is engaged with a global social policy approach that covers basic risks through the following minimum guarantees (ILO and WHO 2009):

- Universal access to healthcare, including maternity care.

- A basic level of income security for all children through child benefits or family allowances.

- Basic income support for the working-age poor who cannot earn sufficient income on the labour market (e.g. employment guarantee through public work programmes).

- Basic income security for the active-age population who cannot engage in labour market activities (e.g. benefits oriented towards disability, unemployment, maternity leave and parental care needs).

- Basic income security for the elderly (e.g. pensions).

The SPF guarantees covering the risks are context specific and leave room for flexibility of design and implementation. Countries may decide if all or some of the risks are to be covered on a universal basis, and whether benefits must be granted through contributory social security schemes or based on needs and conditions to be met. Overall, fiscal space, the wealth of a country, institutional capacity and levels of vulnerability often drive the process of establishing an SPF and the benefits to cover the needs.

Three main elements are needed to establish an SPF (ILO and WHO 2009). The first element requires that individuals have access to essential services such as water, nutrition, education and health, among others. The second element is a basic set of essential social transfers that have to be provided in cash or in-kind paid to vulnerable segments of the population. The last element is the development and amendment of the legislative system to uphold and protect the rights of individuals who are likely to be at risk for deprivations.

In addition, the SPF concept integrates a two-dimensional strategy that includes a horizontal perspective aiming towards universal coverage with essential social protection services and a vertical perspective that ensures more extensive and comprehensive coverage as countries develop fiscal and policy space. The SPF strategy endorsed by the United Nations (ILO 2012) integrates a multidimensional perspective of vulnerability (de Neubourg et al. 2018), leaving countries with the flexibility of adopting policies in a sequential manner, according to their needs, capabilities and institutional prowess.

The United Nations has developed four instruments to assist countries in setting up and maintaining social protection and social transfer services within the framework of the SPF (ILO and WHO 2009). These instruments aim to provide clear guiding principles for estab-

13 The social protection floor initiative may be regarded as a variant of the 100 per cent coverage case at an earlier stage of maturity. However, the International Labour Organization and the United Nations took the SPF initiative to initiate thinking about a minimum package of coverage that also low- and middle-income countries should consider in order to protect their populations. Theoretically, it is not excluded that this minimum package coverage evolves over time into a 100 per cent coverage situation. However, given that the SPF initiative is aimed at poorer countries, it is very unlikely that this evolution will materialise in the near future. Therefore, we present the two options as different regimes in this chapter. 
lishing an SPF in the country. The first instrument is the legal frame, which is embedded in the United Nations (1948) Universal Declaration of Human Rights that promotes a minimum set of guarantees and services essential for human dignity and survival. The second instrument is a set of technical tools that United Nations agencies developed to help countries assess their most pressing social protection needs and evaluate the performance and costs of social transfers. The third instrument includes a set of advisory services, in that United Nations agencies engage in technical and policy support to countries in the design and implementation of SPFs. The fourth instrument includes monitoring tools by institutional bodies that safeguard human rights such as the Office of the High Commissioner for Human Rights. The monitoring process supports countries in reviewing the progress of introducing and maintaining an SPF and contributes to the scaling-up of social protection planning.

An increasing number of countries are incorporating the United Nations-endorsed SPF components into their social protection system. By 2015, the International Labour Organization and other United Nations agencies supported the development of SPFs in 136 countries (ILO 2015). Today, virtually all countries have elements of an SPF in place and efforts are made to extend social protection benefits and coverage within countries (ILO 2017). The effectiveness of SPF components in developed countries is already acknowledged by reliable measures containing poverty and inequality and a sustained economic progress. Estimates show that levels of poverty and inequalities in developed countries would have been 50 per cent higher if not for SPF provisions (ILO 2011). Evidence shows that SPF provisions have the potential to reduce poverty and increase outcomes such as education, employment, empowerment, health and many others (Bastagli et al. 2016). These outcomes reflect the powerful effects of horizontal SPF measures and the wide potential for scaling-up with vertical dimensions of social security.

The SPF is regarded as a vital basis for a social protection system, as it provides a foundation for universal coverage of basic needs while facilitating the movement of people across social assistance and social security forms of insurance.

\subsection{UNIVERSAL BASIC INCOME}

In comparison to the 100 per cent coverage systems, and the SPF, the UBI is a debated idea that aims to cover most of the risks, for most people, with a single intervention. The UBI is a special form of social security and social assistance benefit in that it is intended to be given to everyone of a certain age group, in cash, and independently of wealth, gender, family structure or employment status (see recent studies from Banerjee et al. 2019; Gentilini et al. 2020; Standing 2017; Widerquist 2018). ${ }^{14}$ According to this definition, the UBI is based on three design choices: it is paid to all (universality), without a means test (unconditionality) and in cash (adjustment features linked to amount, frequency and who should benefit). It is regarded as an entitlement linked to citizenship rights and the legal residency of individuals within a country. In that sense the UBI shares these characteristics with universal entitlements

14 For more resources and current studies linked to UBI, please consult 'The idea of universal basic income' repository, by Ugo Gentilini and Jamele Rigolini, at http://pubdocs.worldbank.org/en/ 103921528839429277/SSN-Day8-1pm-Ugo-UBI.pdf 
in social protection that already exist in a number of countries such as universal child benefit or a universal social pension.

There is a broad perception on the risks that UBI intends to cover. The expectation is that UBI will contribute to strengthening social protection by addressing poverty, inequality and associated risks such as those linked to the labour market (e.g. unemployment, low-paying and low-productivity jobs), access to education and health, poorly functioning markets, unequal pay and discrimination in its various forms, among others. A UBI guarantee is therefore expected to bring positive change in the realm of poverty, income inequity and social justice (Cottam 2019). Indeed, studies show that cash transfers to people in the form of a basic income lead to lower inequality, less poverty, more empowerment, economic growth and better health and school outcomes (Bastagli et al. 2016; Sheahen 2012).

Programmes implementing a basic income scheme may do so at the national, regional or local levels. In 2020, no country had a fully fledged UBI scheme in place, but instead many had smaller-scale pilots (e.g. Canada, South Korea, Spain, the Netherlands, Kenya) and a few larger-scale programmes (e.g. China, India, Kuwait, Alaska in the United States, Italy) (Gentilini et al. 2020). In fact, only two countries - Mongolia and Iran - had a nationwide UBI scheme in place, but for a limited period of time. In Mongolia, the entire population received a UBI in the amount of approximately USD 17 per month between 2010 and 2012. Similarly, Iran introduced a UBI scheme in 2011 that granted approximately USD 45 per person per month, and lasted in a variety of forms until 2018. Over the years, many countries around the world have implemented programmes that accommodated a form of UBI. One example is Brazil's Bolsa Familia, a large-scale welfare programme introduced in 2003 that provides a cash transfer to anyone with a declared income below an eligibility threshold. Evidence shows that cash received through Bolsa Familia had a positive effect on children's nutritional outcomes, on the quality of parental care and on the shift of working hours to the formal sector (Bastagli et al. 2016). More recently, Poland introduced the Family 500+ programme in 2016 that includes monetary allocations for both adults and children, satisfying the principle of a UBI scheme (Sowa 2016). In the context of the 2020 COVID-19 pandemic, the Spanish government proposed a UBI programme to shield the population from the effects of the crisis and the programme is expected to roll out for an indefinite period of time (Prochazka 2020).

The arguments against the UBI are varied, but three broad reflections are dominant. One argument emphasises the high cost of UBI for a country (Gentilini et al. 2020). This is especially the case for low-income countries, where low budgets and limited fiscal space may result in large parts of the population not being covered almost by design. The second reflection focuses on the flat structure of the UBI, in that giving cash to all may not serve the redistributive purpose and the expected impact on poverty and inequality reduction in the country (Gentilini et al. 2020). The third argument is based on the 'welfare trap' concept, in that recipients of a basic income may be implicitly encouraged to remain on welfare due to comfort and the absence of incentives to obtain an income via employment (Lagomarsino and Nocetto 2020). Large-scale pilot programmes and experiments have emphasised the net benefits of monetary transfers in relation to costs, with no clear evidence that they induce a welfare trap among targeted populations (Evans and Popova 2014; Lagomarsino and Nocetto 2020). 


\subsection{WORLD BANK SOCIAL SAFETY NETS AND SOCIAL REGISTRIES}

In contrast with the three prototypes discussed above, the SSN approach, as propagated by the World Bank, specifically targets its interventions to the poorest and most vulnerable parts of society. The targeted groups are generally identified using a combination of proxy means testing and community-based targeting. The SSNs comprise non-contributory transfers in cash or in-kind that provide regular welfare support to vulnerable segments of the population. These transfers, also known as social assistance interventions, are part of the broader social protection system of a country that helps people manage risks and shocks and shields them from poverty and destitution.

The SSN programmes are designed to cope with the most severe risks, such as chronic poverty and associated vulnerabilities e.g. those related to food, housing, schooling, care and disability, among others. An SSN programme may use any of the following instruments to alleviate chronic poverty and deprivation among target populations (World Bank 2018):

- Unconditional cash transfers are programmes that do not require any action from beneficiaries to be eligible for the benefit, but they may require that specific criteria are met (e.g. being below the poverty threshold). Examples of unconditional cash transfers are poverty-targeted cash, family, children and orphan allowances, funeral grants and emergency cash support (e.g. refugees).

- Conditional cash transfers are programmes aimed at poverty reduction that require beneficiaries to fulfil some conditions, for instance enrolling children in school, vaccinating children, regular check-ups by a doctor or the like.

- Non-contributory social pensions, also known as cash transfers for the old, are designed to be accessible as a right to everyone who meets the programme requirements. The non-contributory social pensions are unrelated to the work experience of the beneficiary. They integrate programmes such as old-age pensions, disability benefits, war veteran benefits and survival benefits.

- In-kind transfers are benefits in the form of goods and services that provide immediate relief for a given vulnerability. Examples of in-kind benefits are food stamps, rations, vouchers, nutrition programmes (e.g. supplementary feeding) and school supplies (e.g. uniforms, books).

- Public works programmes are public labour initiatives that provide cash or food-based pay to the poor through employment and are designed to smooth income during hardship periods (e.g. recession, period of the year, etc.).

- Fee waivers and targeted subsidies are schemes aimed at smoothing access to vital programmes, services and goods. They include health insurance exemptions, reduced medical fees, education fee waivers, food subsidies, housing allowance, utility allowance, agricultural subsidies and transportation benefits.

- Other transfers such as scholarships, transfers to caregivers who care for children, youth, disabled and older persons.

It is estimated that around a fifth of the global population is part of at least one SSN intervention (World Bank 2014). In 2018, there were 124 countries with SSN spending integrated into the national social protection strategies and planning (World Bank 2018). However, every country now has fragmented elements of an SSN programme in place (World Bank 2018). 
Countries spend on average 1.5 per cent of gross domestic product on SSN programmes, with countries that have stronger welfare systems spending more and fragile states allocating less (World Bank 2018). This means that many of the extremely poor and deprived individuals worldwide still do not have access to SSN interventions. One-third of social assistance recipients live in countries where only 12 per cent of the extremely poor reside (World Bank 2014). In some low-income countries, unaffordability has been referred to as a core inhibiting factor, and they instead rely on smaller-scale donor-financed programmes.

To have a more inclusive effect, the SSNs have to expand progressively in countries that need them the most. The World Bank has already initiated its Social Protection and Labour Strategy 2012-22 (World Bank 2012) to include a strong SSN component. ${ }^{15}$ Within the strategy's framework, it is recognised that SSNs are not a drag on resources but a powerful force that drive economic growth and poverty reduction. The SSN investments need to have country-tailored tools and approaches that would enable the local population to diversify their livelihoods and poverty-exit strategies. A special emphasis is placed on the adaptive side of SSN programmes, to build resilience of households that are more vulnerable to risks and shocks and to adapt the responsiveness of interventions to better meet the needs of those affected by vulnerability on the ground.

To support the SSN programmes and their implementation, the World Bank supports the organisation of social registries, ${ }^{16}$ an information system that supports outreach, intake, registration and determination of potential eligibility for one or more SSN programmes in different countries around the globe (Leite et al. 2017). The social registries ${ }^{17}$ serve as both inclusion and information systems. For national policy actors, the social registries provide information on the assessment of needs, conditions and outreach of social programmes. For individuals, the social registries are an information gateway, in that they provide guidelines on how and where individuals and families can register for inclusion in programmes and what documentation is needed for enrolment. The data gathered through social registries are used by countries to monitor and evaluate demand for interventions, and the planning and costing of SSN programmes. At least 23 developing countries have a social registry in place, with several others planning to establish one (World Bank 2018). Some social registries have near universal coverage (e.g. Chile, Colombia, Pakistan), while others cover up to half of the population (e.g. Georgia, Montenegro, Turkey), with some operating on a much smaller scale (e.g. Mali, Senegal, Yemen) (Leite et al. 2017).

15 The World Bank's strategy, results, and documentation on social safety nets, including the annual review of 'The State of Social Safety Nets' can be consulted at https://www.worldbank.org/en/topic/ safetynets

${ }_{16}$ To follow up on updates on Social Registries, please consult the webpage of World Bank's Collaboration for Development coalition at www.collaboration.worldbank.org

17 Social registries are an important element of the SSN approach as they define the target population for all current, future and potential emergency benefits. Social registries illustrate the quintessential element of the SSN: social protection is for poor people - once one has identified, the target group for all social protection interventions is known. 
Table 11.1 Social system toolkit

\begin{tabular}{|c|c|c|c|c|c|c|c|c|c|}
\hline Risk & $\begin{array}{c}\text { Population } \\
\text { affected } \\
\text { (absolute } \\
\text { number) }\end{array}$ & $\begin{array}{c}\text { Population } \\
\text { affected (as } \\
\text { percentage } \\
\text { of total } \\
\text { number) }\end{array}$ & $\begin{array}{c}\text { Percentage } \\
\text { of } \\
\text { population } \\
\text { affected }\end{array}$ & $\begin{array}{c}\text { Policy } \\
\text { instruments } \\
\text { deployed }\end{array}$ & $\begin{array}{c}\text { Population } \\
\text { affected } \\
\text { by policy } \\
\text { instruments } \\
\text { (absolute } \\
\text { number) }\end{array}$ & $\begin{array}{l}\text { Population } \\
\text { affected } \\
\text { by policy } \\
\text { instruments } \\
\text { deployed }\end{array}$ & $\begin{array}{c}\text { Effectiveness } \\
\text { (population } \\
\text { affected } \\
\text { by risk/ } \\
\text { population } \\
\text { affected by } \\
\text { policy) }\end{array}$ & $\begin{array}{c}\text { Costs of } \\
\text { policy } \\
\text { instruments } \\
\text { (total yearly } \\
\text { costs) } \\
\end{array}$ & $\begin{array}{c}\text { Efficiency } \\
\text { (total } \\
\text { yearly/total } \\
\text { number } \\
\text { of people } \\
\text { affected by } \\
\text { policy) } \\
\end{array}$ \\
\hline A & & & & 1 & & & & & \\
\hline A & & & & 2 & & & & & \\
\hline A & & & & 3 & & & & & \\
\hline B & & & & 1 & & & & & \\
\hline B & & & & 2 & & & & & \\
\hline
\end{tabular}

Source: Authors' own.

\subsection{CONCLUDING REMARKS: MAPPING SOCIAL PROTECTION SYSTEMS}

A systematic approach to social protection is useful because it can direct attention towards providing adequate protection to all residents (citizens) when they need it and thus make sure that the safety net is woven as tightly as possible given the economic constraints and social and political preferences. A systematic approach to social protection is also meaningful because it provides an overview of risks and parts of the population that could be covered at lower cost by avoiding duplications and inconsistencies and thus making the social protection portfolios of countries both more effective and more efficient.

A first step in providing a systematic approach is mapping the elements of the existing system. A valuable way to proceed on that path is by using a simple matrix, as presented in Table 11.1. Filling this matrix for a number of years provides the first basis on which to describe and evaluate the social protection system in a particular country. A full mapping needs to include further information on eligibility criteria, benefit levels and adequacy, institutional capacities and financing. In 2018, the OECD published a Social System Toolkit; the toolbox elaborates the requirements of a comprehensive social system analysis.

Mapping and analysing a social protection system are never purely technocratic exercises. Making decisions on reforms and improvements unavoidably implies answering some difficult, broader social and political questions, including:

- How much of risk taking is a society willing to accept?

- What is, consequently, the socially desirable mixture of preventive, mitigating and coping instruments to be used?

- How much responsibility and financial burden are to be faced by public authorities and how much is the society willing to leave it to individual decisions?

These questions point to the very content and scope of the solidarity contract that a society is willing to accept. Framed differently: how far are members of a society willing to pool their risks and their resources? Social protection systems analysis facilitates the discussion about how to organise these choices in an effective and efficient way but does not provide an answer to basically ideological and political questions. 


\section{REFERENCES}

Arts, W. and J. Gelissen (2010). Models of Welfare State: The Oxford Handbook of the Welfare State. Oxford: Oxford University Press.

Banerjee, A., P. Niehaus and T. Suri (2019). Universal basic income in the developing world. NBER Working Paper. Cambridge, MA: National Bureau of Economic Research.

Bastagli, F., J. Hagen-Zanker, L. Harman, V. Barca, G. Sturge, T. Schmidt and L. Pellerano (2016). Cash transfers: What does the evidence say? A rigorous review of programme impact and of the role of design and implementation features. www.odi.org/publications/10505-cash-transfers-what-does -evidence-say-rigorous-review-impacts-and-role-design-and-implementation

Chef du Gouvernement du Maroc and UNICEF (2016). Vision Intégrée de la Protection Sociale au Maroc. Rabat.

Cottam, H. (2019). Radical Help: How We Can Remake the Relationships between Us and Revolutionise the Welfare State. London: Virago.

de Neubourg, C. (2002). The welfare pentagon and the social management of risks. In R. Sigg and C. Behrendt (eds), Social Security in the Global Village. New Brunswick, NJ: Transaction Publishers, 313-31.

de Neubourg, C. and C. Weigand (2000). Social policy as social risk management. Innovation: The European Journal of Social Sciences 13 (4), 401-12.

de Neubourg, C., J. Castonguay and K. Roelen (2007). Social safety nets and targeted social assistance: Lessons from the European experience. World Bank, Social Protection Discussion paper No. 0718.

de Neubourg, C., L. Boon, V. Cebotari, A. Dangeot, E. Elezaj, M. Isaurralde et al. (2018). Multidimensional child poverty analyses and child-sensitive social protection. Policy in Focus 15 (3), $13-16$.

Esping-Andersen, G. (1990). The Three Worlds of Welfare Capitalism. Princeton, NJ: Princeton University Press.

Evans, D.K. and A. Popova (2014). Cash transfers and temptation goods: A review of global evidence. Policy Research Working Paper 6886. http://documents.worldbank.org/curated/en/ 617631468001808739/Cash-transfers-and-temptation-goods-a-review-of-global-evidence

Fraser, D. (2017). The Evolution of the British Welfare State. London: Palgrave.

Gentilini, U., M. Grosh, J. Rigolini and R. Yemtsov (eds) (2020). Exploring Universal Basic Income: A Guide to Navigating Concepts, Evidence, and Practices. Washington, DC: World Bank.

GIZ (2020). Developing and integrating social protection systems. www.giz.de/en/worldwide/32524.html

Holzmann, R. and S. Jorgensen (1999). Social Protection as Social Risk Management. Washington, DC: World Bank.

ILO (2011). Social Protection Floor for a Fair and Inclusive Globalization: Report of the Social Protection Floor Advisory Group. Geneva: International Labour Office.

ILO (2012). Social protection floors recommendation. International Labour Organization. 202. www.ilo .org/dyn/normlex/en/f?p=NORMLEXPUB:12100:0::NO::P12100_ILO_CODE:R202

ILO (2015). Building social protection floors for all. www.social-protection.org/gimi/gess/RessourcePDF .action? ressource.ressourceId $=51737$

ILO (2017). World social protection report 2017-19: Universal social protection to achieve the Sustainable Development Goals. www.social-protection.org/gimi/gess/RessourcePDF.action ?ressource.ressourceId $=54887$

ILO (2020). World social protection report. Geneva.

ILO and WHO (2009). The social protection floor. www.un.org/en/ga/second/64/socialprotection.pdf

Lagomarsino, A. and L. Nocetto (2020). Do cash assistance programs create welfare traps? https:// scholar.harvard.edu/files/alagomarsino/files/lagomarsinojmp.pdf

Leite, P., T. George, C. Sun, T. Jones and K. Lindert (2017). Social registries for social assistance and beyond: A guidance note and assessment tool. http://documents.worldbank.org/curated/en/ 698441502095248081/pdf/117971-REVISED-PUBLIC-Discussion-paper-1704.pdf

Mercader-Prats, M. and H. Levy (2004). The role of tax and transfers in reducing personal income inequality in Europe's regions: Evidence from EUROMOD. EUROMOD Working Papers EM9/04.

MISSOC (2020). Mutual information system on social protection. Brussels: European Union. 
Notten, G. and C. de Neubourg (2011). Monitoring absolute and relative poverty: 'Not enough' is not the same as 'much less'. Review of Income and Wealth 57 (2), 247-69.

OECD (2018). Social protection system review: A toolkit. Paris. https://doi.org/10.1787/25183702

OECD (2020). Database on income inequality. Paris. https://data.oecd.org/inequality/income-inequality.htm

Prochazka, T. (2020). Spain may issue 'permanent' basic income to fight COVID-19. BIEN, 7 April. https://basicincome.org/news/2020/04/spain-may-issue-permanent-basic-income-to-fight-covid-19/

Sheahen, A. (2012). Basic Income Guarantee: Your Right to Economic Security. New York: Palgrave.

Sowa, A. (2016). 'Family 500+': A new family income-supporting benefit in Poland. ESPN Flash Report $206 / 45$.

Standing, G. (2017). Basic Income: A Guide for the Open-Minded. New Haven, CT: Yale University Press.

Trattner, W. (1999). From Poor Laws to Welfare States. New York: Free Press.

United Nations (1948). The Universal Declaration of Human Rights. www.un.org/en/universal -declaration-human-rights/

van Kersbergen, K. and B. Vis (2014). Comparative Welfare State Politics. Cambridge: Cambridge University Press.

Vis, B. (2010). Politics of Risk-Taking: Welfare State Reform in Advanced Democracies. Amsterdam: Amsterdam University Press.

Widerquist, K. (2018). A Critical Analysis of Basic Income Experiments for Researchers, Policymakers, and Citizens. New York: Palgrave Macmillan.

World Bank (2012). The World Bank 2012-2022 social protection and labor strategy. http:// siteresources.worldbank.org/SOCIALPROTECTION/Resources/280558-1274453001167/7089867 -1279223745454/7253917-1291314603217/SPL Strategy 2012-22 FINAL.pdf

World Bank (2014). The state of social safety nets 2014 . Washington, DC: World Bank. http://hdl.handle .net/10986/18376

World Bank (2018). The state of social safety nets 2018. Washington, DC: World Bank. http://hdl.handle .net/10986/29115 